\title{
The immune system on the TRAIL of Alzheimer's disease
}

\author{
Chiara Burgaletto ${ }^{1}$, Antonio Munafò ${ }^{1}$, Giulia Di Benedetto ${ }^{1}$, Cettina De Francisci ${ }^{1}$, Filippo Caraci ${ }^{2,3}$, \\ Rosaria Di Mauro ${ }^{1,4}$, Claudio Bucolo ${ }^{1}$, Renato Bernardini ${ }^{1,4^{*}}$ and Giuseppina Cantarella ${ }^{1}$
}

\begin{abstract}
Alzheimer's disease (AD) is the most common form of dementia, characterized by progressive degeneration and loss of neurons in specific regions of the central nervous system. Chronic activation of the immune cells resident in the brain, peripheral immune cell trafficking across the blood-brain barrier, and release of inflammatory and neurotoxic factors, appear critical contributors of the neuroinflammatory response that drives the progression of neurodegenerative processes in AD. As the neuro-immune network is impaired in course of AD, this review is aimed to point out the essential supportive role of innate and adaptive immune response either in normal brain as well as in brain recovery from injury. Since a fine-tuning of the immune response appears crucial to ensure proper nervous system functioning, we focused on the role of the TNF superfamily member, TNF-related apoptosisinducing ligand (TRAIL), which modulates both the innate and adaptive immune response in the pathogenesis of several immunological disorders and, in particular, in AD-related neuroinflammation. We here summarized mounting evidence of potential involvement of TRAIL signaling in AD pathogenesis, with the aim to provide clearer insights about potential novel therapeutic approaches in AD.
\end{abstract}

Keywords: Immune response, Neuroinflammation, Proinflammatory cytokines, Regulatory T cells

\section{Background}

Alzheimer's disease (AD) is an age-related neurodegenerative disorder with an insidious onset characterized by cerebral atrophy and progressive cognitive decline [1]. The acknowledged neuropathological hallmarks of $\mathrm{AD}$ are represented by extracellular senile plaques, composed of amyloid- $\beta$ (A $\beta$ ) peptide and intracellular neurofibrillary tangles (NFTs) generated by hyperphosphorylated protein tau [2].

Growing evidence suggests that the multifactorial pathophysiological mechanisms of $\mathrm{AD}$ is not restricted to the neuronal compartment, as relevant role has been

\footnotetext{
* Correspondence: bernardi@unict.it

'Department of Biomedical and Biotechnological Sciences (BIOMETEC),

Section of Pharmacology, University of Catania, Via Santa Sofia 97, Catania, Italy

${ }^{4}$ Clinical Toxicology Unit, University Hospital, University of Catania, Catania, Italy

Full list of author information is available at the end of the article
}

attributed to the tight interactions of immunological mechanisms within the brain [3].

Since decades, active research has investigated network connections between the immune system and the nervous system. In fact, it has been described a reciprocal functional control between the immune system and the central nervous system (CNS) [4], a mechanism essential to tissue repair and regeneration as well as removal of damaged tissues and cells [5]. A low-grade peripheral immune/inflammatory response and the basal release of cytokines are needed to maintain brain homeostasis and functional plasticity, including hippocampal-dependent cognitive functions and neurogenesis, suggesting that the systemic immune response exerts a healing role in the CNS $[6,7]$.

Now, it is a common notion that systemic inflammatory disorders may be associated with cognitive decline [8], and, in fact, chronic inflammation is known to 
inhibit neuronal functions and contribute to onset and progression of AD [9]. In this line, robust data support the crucial relevance of mediators of the inflammatory/ immune response in neurodegeneration, as, for instance, injured neurons release arrays of these molecules, which redundantly sustain neuronal damage and death [10].

Cytokines belonging to the tumor necrosis factor (TNF) superfamily are considered substantial contributors of the accelerated cell death rate which characterizes neurodegenerative processes. Among these, the proapoptotic/proinflammatory cytokine Tumor necrosis factor-related apoptosis-inducing ligand (TRAIL), first discovered as a tumor cell killer, is expressed in macrophages, $\mathrm{T}$ lymphocytes, neutrophils, and dendritic cells [11, 12].

TRAIL, which acts through two death receptors referred to as DR4 and DR5, is a potent mediator of prominent neuronal loss induced in both chronic and acute neurodegenerative processes, including those related to $A \beta$ accumulation [13], trauma [14], and brain ischemia [15, 16], consistent with boosted peri-damage neuroinflammation.

Furthermore, sustained TRAIL expression appears related to functional decline in animal models of $\mathrm{AD}$ [17]. In fact, its immunoneutralization by means of a monoclonal antibody is associated with a significant rescue of neurons from death [13], reduced accumulation of $A \beta$ and attenuated expression of inflammatory/immune mediators [17], paralleled by a re-balance of both central, and peripheral immune response [18].

In synthesis, TRAIL efficiently sets into motion and sustain neurodegeneration-related neuroinflammation, as its neutralization implies significant attenuation of inflammatory processes [19], corroborating the hypothesis that is represents an important molecular clue to $A \beta$ dependent neurodegenerative processes, and may thus well be envisioned as a potential candidate target for innovative immunotherapeutic strategies in $\mathrm{AD}$.

\section{The impact of central and peripheral inflammatory/ immune response in Alzheimer's disease}

Neurodegenerative disorders share selective neuronal vulnerability in specific brain regions, which is related to the neuronal responses to detrimental stimuli, such as, for instance, disease-related misfolding proteins, that finally become unsupportive to neurons [20].

In addition to the pathogenetic role of $A \beta$ and tau proteins in $\mathrm{AD}$, recent evidence favors the hypothesis that the immune system plays a pivotal role in the onset and progression of this disease [21].

In fact, neuronal damage in $\mathrm{AD}$ is associated with chronic activation of the CNS-resident innate immune cells and increased peripheral leukocyte access across the blood-brain barrier (BBB) [22], consistent with the demonstration of a functional meningeal lymphatic system [23], as well as of a substantial peripheral immunocyte trafficking through the choroid plexus $(\mathrm{CP})$ [24], supporting the notion of a cross-talk system between peripheral and CNS immunocytes.

Moreover, the innate immune system indeed represents the first line of defense against pathogens serving as a link to adaptive $\mathrm{T}$ and $\mathrm{B}$ cells, by means of antigen presentation processes and transfer of information [25, 26], and in this line, both branches of immune response, adaptive, and innate, may affect the neuroinflammatory process and related progression of neurodegeneration in $\mathrm{AD}$ and other CNS disorders [27].

It is well-established that microglia and astrocytes, the predominant innate immune cells in the CNS, are strongly implicated in aberrant molecular pathways that underlie AD pathogenetic alterations [10].

Microglial cells represent the major immunological effector of the innate immune system in the brain and mediate functions such as tissue surveillance, removal of pathogens, and response to injury [28, 29], also contributing to neuronal survival and synaptogenesis [30].

Under resting condition, microglia are characterized by a ramified morphology and a weak antigenpresenting activity, partly due to low level of expression of the major histocompatibility complex (MHC) on its surface [31]. Activated microglia eventually convert to an amoeboid-like morphology which displays upregulated expression of both MHC and co-stimulatory molecules involved in antigen presentation, leading to interactions with peripheral immune cells [32].

Upon injury, disease, or inflammation, healthy neurons may get damage, which in turn causes release of selfantigens or aberrant proteins that activate resting microglia (Fig. 1). In fact, pathogenic stimuli break the delicate balance between neurotoxic and neuroprotective mechanisms, inducing microglial activation, triggering for example, the Toll-like receptors 4 (TLR4) signaling pathway and conversion to the pro-inflammatory phenotype [33-35]. The latter microglial state is characterized, not only by a morphological changes, but also by release of pro-inflammatory molecules, such as interleukin-1 beta (IL-1 $\beta$ ), interleukin-6 (IL-6), tumor necrosis factor alpha (TNF $\alpha$ ), interferon gamma (IFN- $\gamma$ ), chemokines, as well as reactive oxygen and nitrogen species (ROS/ RNS), which promote diapedesis of peripheral leukocytes through the BBB, further contributing to fuel local detrimental inflammatory response $[28,36]$.

In addition to its pro-inflammatory pattern, microglia can also adopt an alternative activation pathway [37], associated with increased production of anti-inflammatory cytokines and neurotrophic factors to facilitate phagocytosis of cell debris and promote neuronal repair and survival $[38,39]$.

In the occurrence that innate immune-related processes are not completely resolutive and the inflammatory 


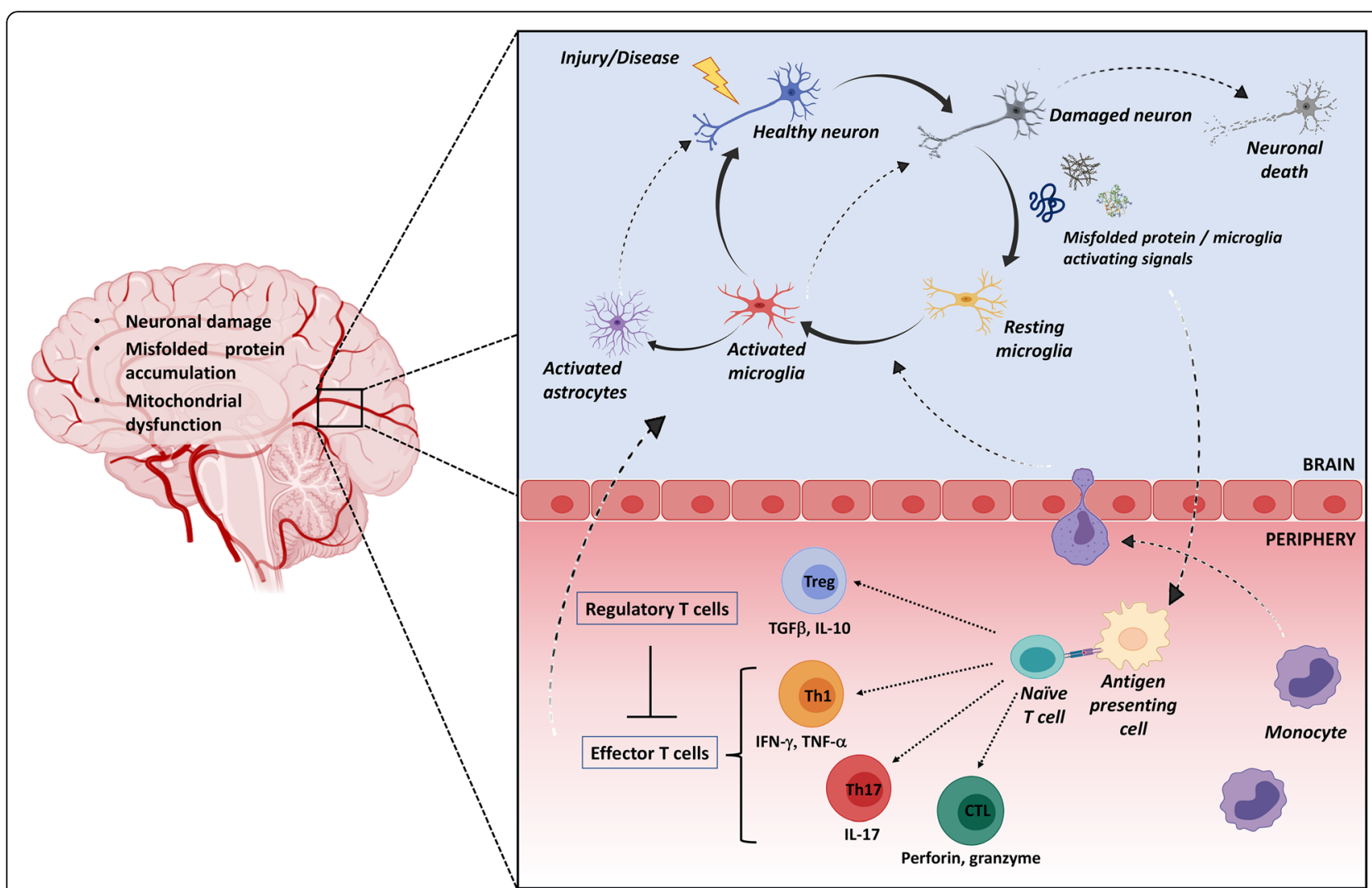

Fig. 1 Central and peripheral inflammatory/immune response in neurodegeneration. Upon injury, disease, or inflammation, damaged neurons could release self-antigens or modified proteins that activate resting microglia. Activated microglia responds to these stimuli, by production of proinflammatory cytokines and chemokines, reactive oxygen, and nitrogen species. When such first innate immune-related process is not completely resolutive and the inflammatory stimuli persist, the microglia-mediated mechanisms remain trapped in a vicious cycle, characterized by chronic pro-inflammatory cytokine production linked to a cascade of neurotoxic events leading to neuronal death. Substantial recruitment of monocytes into the $A D$ brain begins when $A \beta$ deposition and associated neuronal damage triggers a local immune response, activating astrocytes and microglia. Activated pro-inflammatory microglia also release astrocyte-activating signals which induce neuroinflammatory astrocytes that, in turn, amplify the neurodegenerative cycle. In addition, misfolded proteins not adequately removed may drain into peripheral lymphoid tissues, wherein they are presented by antigen presenting cells to naïve $T$ cells, thereafter mounting an adaptive immune response against these antigens. Depending upon antigen-presenting cell signals, naïve T cells differentiate into antigen-specific T effector cells (Th1, Th2, Th17, and cytotoxic T lymphocytes (CTL) or regulatory T (Treg) cells). Specifically, Th1 and Th17 cells cross the blood-brain barrier and directly contribute to neuroinflammation through the production of neurotoxic and proinflammatory factors that act on glial cells. Consequently, activated microglia and astrocytes respond by releasing high amounts of chemokines that assist the infiltration of a second wave of effector T cells into the brain. CD8+ CTLs recognize antigen presented by MHC class I on neurons to induce perforin- and/or granzyme-mediated cytolysis. In response to inflammatory events, Treg cells dampen down neuroinflammation and neurodegeneration

stimuli persist, microglia-mediated mechanisms are trapped in a vicious cycle, characterized by chronicized release of pro-inflammatory cytokine initiating a cascade of toxic events leading to neuronal death [40].

Although microglia represent the main mediators of brain immune surveillance, under pathological conditions the infiltrating monocytes transiently supplement the brain mononuclear phagocyte compartment (microglia itself) playing a major role in controlling neuropathological events in the CNS [41, 42]. Notably, infiltrated monocytes contribute to tissue repair, inflammation resolution, and production of neurotrophic factors [41].

Astrocytes, the other major innate effector cells in the CNS, contribute to maintainance of CNS homeostasis and sustain neuronal survival through the release of metabolites and neurotrophic factors essential for normal brain functions and organized cognitive activity [43], and they also safeguard BBB structural integrity and permeability, eventually exerting gate-controlled recruitment of peripheral immune cells into the brain parenchyma [44].

Recent work has highlighted the pathophysiological relevance of the microglia-astrocyte crosstalk [45]. In particular, activated microglia releases specific astrocyteactivating signal molecules, such as interleukin-1 alpha (IL-1 $\alpha)$, TNF $\alpha$, and complement component 1q (C1q), all inductors of a neuroinflammatory reactive astrocyte phenotype, which, similarly to activated microglia, highly 
express many complement components, including MHC class II molecules [46, 47], as well as an array of cytokines and chemokines that act as chemoattractants, crucial for the recruitment of $\mathrm{T}$ cells into the CNS [48-50].

In addition, also adaptive immune cells infiltrating the brain parenchyma seem able to support the neuroinflammatory process [51], as demonstrated for $\mathrm{B}$ and $\mathrm{T}$ lymphocytes, which are endowed with protective functions from pathogens and trigger a fast specific immune response in case of repeated infections due to the same agent [52].

Under conditions of neurodegeneration, high frequencies of $\mathrm{T}$ lymphocytes have been found to infiltrate the brain parenchyma, suggesting a critical pathophysiological role [53]. In fact, the chronic neuroinflammatory status associated with neurodegenerative disorders and driven by the main reactive components of the CNS affects the structural integrity and the permeability of $\mathrm{BBB}$, enhancing transmigration of peripheral immune cells into the CNS and diffusion of inflammatory molecules across the BBB [54-56], thus contributing to the development and progression of lesions [57, 58]. Nevertheless, it has been shown that the $\mathrm{CP}$ of the bloodcerebrospinal fluid barrier (BCSFB) works mainly as a selective gateway for leukocyte entry, rather than a firm barrier (BBB) for immune surveillance. Schwartz and colleagues proposed $\mathrm{CP}$ as a selective and "educative" gate for recruitment of leukocytes to the inflamed CNS parenchyma [40]. This hypothesis is supported by the findings that neutrophils, monocytes, and $\mathrm{T}$ cells enter the injured CNS through the BCSFB in response to brain parenchyma damage [59].

$\mathrm{T}$ cells can be classified into CD4+ $\mathrm{T}$ cells, main regulators of the immune response, and $\mathrm{CD} 8+\mathrm{T}$ cells, designated as cytotoxic $\mathrm{T}$ cells for their ability to remove damaged and infected cells [60].

Depending either upon specific stimuli, tissue environment and antigen-presenting cell signaling, naïve CD4+ $\mathrm{T}$ cells (Th0) differentiate into antigen-specific $\mathrm{T}$ effector including T-helper1 (Th1), T-helper2 (Th2) and Thelper17 (Th17) cells, as well as cytotoxic T lymphocytes (CTLs), or regulatory $\mathrm{T}$ cells (Tregs). While Th1 and Th17 cells, which are overactivated in neurodegenerative disorders [61], directly contribute to neuroinflammation through the release of pro-inflammatory cytokines (IFNY, TNF $\alpha$, and IL-17) and other inflammatory mediators, Th2 cells, produce anti-inflammatory cytokines (e.g., IL-4), and, for this reason, they have been considered for development of potential intervention strategies [62]. Both Th1 and Th2 cells, are essential for the maintenance of a healthy CNS environment, as an altered Th1/Th2 ratio has been regarded as a causative event in neurodegeneration [63].

Moreover, also antigen-specific CD8+ CTLs have been shown to participate to the pathophysiology of chronic inflammatory disorders includeed those related to neurodegeneration, through production of cytolysis mediators such as perforins and granzymes [64, 65].

Another cell subset, Treg cells have been shown to dampen down neuroinflammation by inhibiting antigen presentation, and upregulating glial neurotrophic factors [66]. As immunoregulatory cells, Tregs release antiinflammatory factors, such as interleukin-10 (IL-10), and transforming growth factor beta (TGF $\beta$ ), that suppress activation of effector $\mathrm{T}$ lymphocytes, assuming a key role in the development and maintenance of immune tolerance [67].

Because of their immunosuppressive properties, Treg cells, extensively studied in autoimmune disorders [68], actually represent potential elements for improvement of the outcome in neurodegenerative disorders $[69,70]$.

Recently, the possibility of a dual role of Tregs in the progression of $\mathrm{AD}$ has been object of debate. In this condition, Tregs may have a beneficial role at early disease stages, restraining detrimental gliosis, promoting beneficial activation of microglia, and allowing leukocyte re-trafficking through $\mathrm{CP}$ [71].

A deficit of TGF- $\beta 1$, the main cytokine produced by Tregs, can critically contribute to neuroinflammation in $\mathrm{AD}$ brain $[72,73]$. Additional preclinical studies in experimental models of $\mathrm{AD}$ are needed to understand whether Treg cells might exert neuroprotective effects in an early phase of the amyloid-related neurodegeneration by rescue of TGF- $\beta 1$.

On the other hand, at later disease stages, Tregs appear to take over a detrimental function, by altering $\mathrm{CP}$ function and reducing the recruitment of inflammationresolving leucocytes to CNS [74].

\section{TRAIL: a potent, pleiotropic fine-tuning effector of the immune response}

TRAIL, also known as TNFSF10, is a pleiotropic cytokine belonging to the TNF superfamily, involved in many peripheral and CNS functions, including cell death signaling pathway, immune response, and inflammation [75].

TRAIL can be detected as a soluble and type II transmembrane protein $[76,77]$. The homotrimeric and biologically active form is able to interact with a complex system of receptors with different signaling outcomes, from pro-apoptotic to prosurvival/proliferative effects $[78,79]$.

In humans, TRAIL binds two death-inducing receptors, DR4/TRAIL-R1 and DR5/TRAIL-R2, which contain a functional intracellular death domain, and two transmembrane decoy receptors (DcRs), DcR1/TRAIL-R3 and DcR2/TRAIL-R4, which downregulate the activity of the former receptors by sequestration of the bioactive ligand [80]. Finally, TRAIL has also been shown to bind with very low affinity to osteoprotegerin (OPG), a secreted 
member of the TNF receptor family involved with the regulation of bone turnover, which acts as a soluble neutralizing receptor $[81,82]$. Unlike humans, mice express only three TRAIL receptors: DR5, DcR1, and DcR2 [83, 84].

Two TRAIL-activated death pathway have been identified: an extrinsic pathway, linked to caspase-8 activation, through the recruitment of the adaptor molecule Fasassociated death domain protein (FADD), and an intrinsic mitochondrial pathway in which effector caspases are activated after a BH3 interacting-domain (Bid)-mediated signaling cascade causing mitochondrial outer membrane permeabilization, and the release of cytochrome $\mathrm{c}$ which promotes the formation of multimeric complex called "apoptosome" [85].

Several studies suggest the existence of a crosstalk between the two pathways, as demonstrated by the evidence that Bid is cleaved by active caspase-8 [86].
Since its discovery, TRAIL has been extensively studied in the cancer area because of its ability to induce selective apoptosis in a wide variety of tumor cell lines [87]. While the latter has long represented the best characterized function of TRAIL, increasing evidence suggest that TRAIL mediates several alternative functions in normal cells [88]. In fact, TRAIL can stimulate also prosurvival pathways, through factors such as nuclear factor

B (NF- B) and Akt [89]. In addition, TRAIL promotes proliferation and migration of endothelial cells, suggesting its role in endothelial cell physiology and in the pathophysiology of the vascular system $[90,91]$.

Among others, a major role of TRAIL appears related to the fine-co-tuning of the immune response in the CNS (Fig. 2).

TRAIL is not costitutively expressed in the normal brain, which, instead, expresses its receptors [92], while under inflammatory brain conditions, TRAIL is

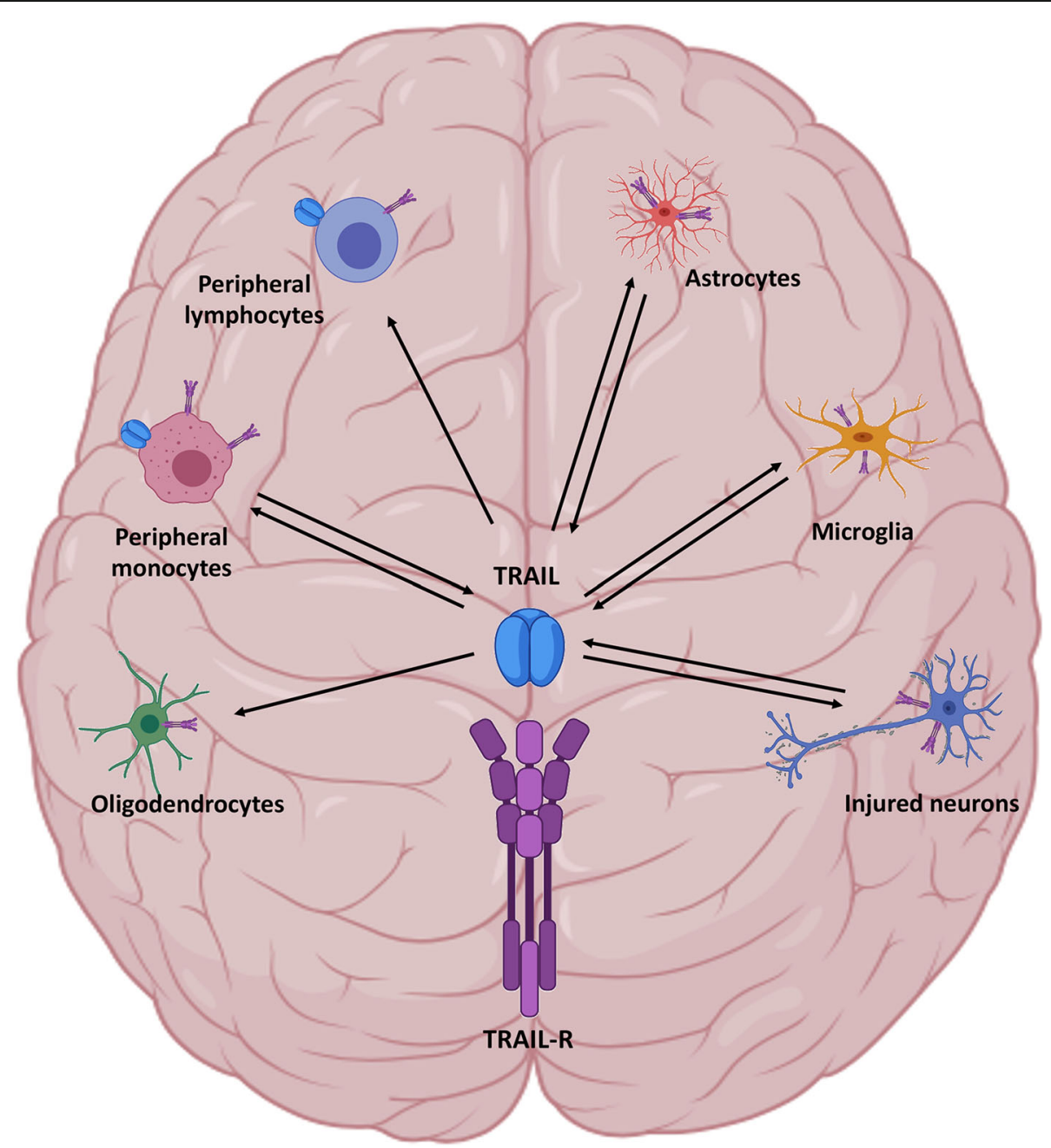

Fig. 2 Fine-tuning of immune response by TRAIL in the brain. Under brain inflammatory conditions, TRAIL is abundantly released by activated glia, infiltrated peripheral monocytes and injured neurons. TRAlL acts as a potential death signal by interacting with its receptors expressed in neurons, microglia, monocytes, lymphocytes, astrocytes, and oligodendrocytes 
abundantly released by activated glia [93], CNSinfiltrating macrophages [94], and damaged neurons [13] acting as a potential cell death signal after interacting with TRAIL receptor-expressing cells resident in the CNS [92, 95-97].

An interesting aspect of TRAIL is its involvement in the homeostatic regulation of the immune system, as in fact, it is expressed on various innate and adaptive immune cell types [98], including monocytes, macrophages, natural killer cells, natural killer $\mathrm{T}$ cells, dendritic cells, and neutrophils after stimulation with lipopolysaccharide and pro-inflammatory cytokines such as IFN $\alpha$, IFN $\beta$, and IFN $\gamma$, as well as on $\mathrm{T}$ lymphocytes following $\mathrm{T}$ cell receptor (TCR)-mediated activation [99-104]. In contrast to the ligand, TRAIL-receptors are ubiquitously expressed also outside the immune system [105], and, for this reason, TRAIL seems to substantially modulate both the immune responses and their cellular components via the apoptotic cell-death pathway [106], and to participate to the immune response in different tissues and conditions [107-110].

Nevertheless, the immune system employs apoptosis not only as a self-restricting regulatory mechanism but also as an effector mechanism of immune-competent cells which can selectively eliminate virus-infected, transformed cells [111], and also normal cells in case of autoimmune inflammation [97], or in post-transplantion disorders [112]. TRAIL also represents an effector of immune-surveillance function and contribute to apoptosis of tumor and virus-infected cells [84].

TRAIL-induced apoptosis is involved in various processes, such as removal of lymphocytes with dangerous self-reactive specificities (autoreactive $\mathrm{T}$ and $\mathrm{B}$ cells) [113] and infiltrating immune cells [114, 115]. Data from studies carried out on TRAIL-deficient animal model suggest that TRAIL is essential for the maintenance of central immune tolerance by an indirect negative selection of autoreactive thymocytes $[106,116]$. Additionally, TRAIL is involved in the regulation of peripheral tolerance by apoptosis-induction in mature lymphocytes after sensitization with IL-2, as well as by promoting the proliferation of Treg cells, elements with an essential role in maintaining immune tolerance $[117,118]$. TRAIL increases anti-inflammatory Treg cell population as demonstrated by recent in vivo studies with systemically administered long-acting PEGylated TRAIL [119].

Moreover, TRAIL affects immune cells not only by inducing apoptotic death, but also by inhibiting their activation and expansion [120] as it directly inhibits $\mathrm{T}$ cell activation, suppresses $\mathrm{T}$ cell proliferation, and production of T cell-derived proinflammatory cytokines [108].

Finally, TRAIL system regulates innate and adaptive immune responses playing a role of crucial relevance in autoimmune and inflammatory diseases [11, 121, 122], as well as in immune surveillance in virtually all tissue and organs, including the CNS [123].

\section{TRAIL: a conductor of the inflammatory/immune orchestra in Alzheimer's disease?}

$\mathrm{AD}$ represents one of the greatest future global healthcare challenges. Owing to the increasing life expectancy in the general population and the consequent rising $\mathrm{AD}$ prevalence, this widely diffused disorder has become a major concern [124].

Neuropathologically, AD is characterized by the presence of amyloid plaques in the brain, as well as intracellular NFTs generated by hyperphosphorylated forms of the protein tau $[2,125]$, and in addition, by an inflammatory/immune response susceptibility, which plays a major role in various phases of the disease from its onset to later, progressive stages $[21,126]$.

It is noteworthy that neuroinflammatory foci in the $\mathrm{AD}$ brain localize in close vicinity of $\mathrm{A} \beta$ plaques, and they are associated with glia activation [127] and release of mediators of the inflammatory/immune response [128], including, among others, pro-inflammatory cytokines [129].

In this regard, TRAIL with its prominent death signaling and potent immune modulating properties [11] assumes an orchestrating role in the complex scenario of the AD brain.

TRAIL, specifically expressed in the human AD brain [130], is abundantly released by human neural cells challenged with $A \beta$ in vitro [13] and activated glia [131], and is also associated with reduced expression of the $\mathrm{Na}+$ $\mathrm{Ca} 2+$ exchanger neuroprotective isoform NCX3, with a subsequent reduction of the energetic supply to neurons, in such manner providing redundant contribution to its potent proapoptotic effect in course of neurodegenerative process [132].

Growing evidence suggest that TRAIL has a relevant coordinating function in the inflammatory roundabouts of $\mathrm{AD}$, while it also directly mediates $\mathrm{A} \beta$-related neurotoxicity (Table 1) [13, 14]. In fact, it has been demonstrated that immunoneutralization of TRAIL is associated with rescue from death of human neuronal cells challenged in vitro with $A \beta[13]$, and that blockade of the DR5 TRAIL-death receptor signaling with specific antibodies completely abrogates $\mathrm{A} \beta$-induced neurotoxicity in both human neuronal cell lines and primary cortical neurons [133], suggesting a direct, $A \beta$-additive neurotoxic effect of TRAIL in the AD brain. Based on these findings, it has been demonstrated that TRAIL immunoneutralization resulted in functional improvement, reduced deposition of $\mathrm{A} \beta$ and dramatically decreased expression of immune/inflammatory mediators in a transgenic mouse model of $\mathrm{AD}$ which develops progressive, age-related, cognitive decline [17]. 
Table 1 Pathophysiological implications of TRAIL in Alzheimer's disease

\begin{tabular}{|c|c|c|c|}
\hline $\begin{array}{l}\text { Alzheimer's } \\
\text { disease model }\end{array}$ & $\begin{array}{l}\text { TRAlL-based } \\
\text { treatment }\end{array}$ & Main findings & Reference \\
\hline $\begin{array}{l}\text { SH-SY5Y neuronal- } \\
\text { like cells }\end{array}$ & $\begin{array}{l}\text { rTRAIL } \\
\text { TRAIL-neutralizing } \\
\text { monoclonal antibody }\end{array}$ & TRAIL mediates A $\beta$-neurotoxicity in vitro & [13] \\
\hline Human AD brain & / & TRAIL is specifically expressed in Alzheimer's disease brain & [130] \\
\hline $\begin{array}{l}\text { SH-SY5Y neuronal- } \\
\text { like cells } \\
\text { Primary mouse } \\
\text { cortical neurons }\end{array}$ & $\begin{array}{l}\text { anti-TRAIL-R/DR5 } \\
\text { antibody }\end{array}$ & Blockade of TRAIL-death receptor DR5 signaling prevents A $\beta$-neurotoxicity in vitro & [133] \\
\hline $3 \times \operatorname{TgAD}$ & $\begin{array}{l}\text { TRAIL-neutralizing } \\
\text { monoclonal antibody }\end{array}$ & $\begin{array}{l}\text { Neutralization of TRAIL is associated with functional recovery, decreased A } \beta \text { burden and } \\
\text { rebalance of both central and peripheral immune response in vivo. }\end{array}$ & [17] \\
\hline $3 \times \operatorname{TgAD}$ & $\begin{array}{l}\text { TRAlL-neutralizing } \\
\text { monoclonal antibody }\end{array}$ & $\begin{array}{l}\text { Neutralization of TRAIL restrain peripheral and CNS inflammatory/immune response along } \\
\text { with decreased microglial TNFa production, reduced accumulation of both } A \beta \text { and p-Tau } \\
\text { protein in the hippocampus of } 3 \times T \text { T } A D \text { mice. }\end{array}$ & [18] \\
\hline
\end{tabular}

Summary of the most interesting evidences of the involvement of TRAIL in the pathophysiological events related to neuroinflammatory conditions such as Alzheimer's disease, in view of a potential future clinical development of TRAIL-based therapeutic strategies

We have previously mentioned how misfolded proteins, such as $A \beta$, when not adequately removed, may drain into peripheral lymphoid organs, setting into motion and chronically maintaining an immune response [134], which, in turn, can result unbalanced in its outcome. In light of the fact that increased exchange of immunocytes may occur between peripheral lymphoid organs and the brain [135], it is noteworthy that the integrity of the BBB may not necessarily subsists in course of neurodegenerative disorders [136]. In fact, peripheral immunocytes have been indicated as factors that, when the inflammatory/immune equilibrium within the CNS is disrupted, are able to significantly influence progression of the AD brain pathology [74, 137].

Now, considering the pleiotropic role of TRAIL in orchestrating key events of the inflammatory/immune response, it appears of interest how its immunoneutralization also leads to a rebalance of immunocytes ratios, with special regard to the Treg cell population either in the spleen and in the brain [18].

Treg cells, besides their role as "controllers" of the overshooting inflammatory/immune response [138], when not represented in an adequate number, may be hired as causative elements of either hyperinflammatory [139] or proliferative [140] disorders. Thus, it is plausible to hypothesize that Treg cells represent, in a first phase of the response, a key factor in preventing fast progression of overshooting brain inflammation and consequent accelerated neurodegeneration, as a fruit of the adjustment of Treg (and, perhaps, of other immunocytes) flow to the brain, paralleled by decreased amount of $A \beta$ and blunted immune reactivity.

Apparently, after a first attempt of the immune response to restain AD-related brain inflammation by means of TRAIL-driven increase of Treg cells, the latter may assume an overwhelming attitude, thus, limiting the beneficial effects of the immune response against accumulating $A \beta$ [74], allowing the inflammatory response to overshoot, and resulting in noxious effects.

Consistently, central and peripheral immune/inflammatory markers, including specific Treg cells markers FoxP3 and GITR, as well as cyclooxygenase-2 (COX-2), inducible nitric oxide synthase (iNOS), IL- $1 \beta$ and TNF $\alpha$ are restored to basal levels, while, on the other hand, expression of anti-inflammatory cytokines such as IL-10 is significantly upregulated after chronic treatment of transgenic AD mice with anti-TRAIL antibody [18].

Moreover, such TRAIL-related restrain of peripheral and CNS inflammatory/immune response in murine model of $\mathrm{AD}$ occurs along with decreased both microglial TNF $\alpha$ production, along with reduced accumulation of both $A \beta$ and $p$-Tau protein in the hippocampus of 3xTg-AD mice treated with an antiTRAIL antibody [18].

\section{Conclusions}

Redundant, persistent, and self-activating inflammatory processes in the brain undoubtedly represent one main factor fueling the progression of AD.

The concept of a dynamic, balanced modulation of the inflammatory/immune response has a relevant strength that should be exploited for discovery of innovative therapeutic strategies.

The pleiotropic effects of TRAIL appear evident within different outcomes of the inflammatory immune/response, consistently, either in the peripheral lymphoid organs and in the brain. The TRAIL system greatly influences neuronal death rate during neurodegeneration. Secondly, TRAIL also appears to be a connector of peripheral immune response with the degenerating inflamed 
brain, leading to activation of Treg cells and probably driving them to over-respond with detrimental consequences for the $\mathrm{AD}$ brain.

In conclusion, it is plausible to hypothesize that clinically meaningful treatment options for $A D$ could be achieved through pharmacological modulation of the TRAIL system.

\section{Abbreviations}

$A \beta$ : Amyloid-beta; AD: Alzheimer's disease; APCs: Antigen presenting cells; BBB: Blood-brain barrier; BCSFB: Blood-cerebrospinal fluid barrier; C1q: Complement component 1q; CNS: Central nervous system; COX2: Cyclooxygenase-2; CP: Choroid plexus; CTLs: Cytotoxic T lymphocytes; DcRs: Decoy receptors; DR4: Death receptor 4; DR5: Death receptor 5; IFNY: Interferon gamma; IL-10: Interlekin-10; IL-1a: Interleukin-1alpha; IL13: Interleukin-1 beta; IL-6: Interleukin-6; iNOS: Inducible nitric oxide synthase; MHC: Major histocompatibility complex; NFT: Neurofibrillary tangles; OPG: Osteoprotegerin; RNS: Reactive nitrogen species; ROS: Reactive oxygen species; TGFB: Transforming growth factor beta; Th1: T-helper1 cells; Th17: Thelper17 cells; Th2: T-helper2 cells; TLR4: Toll-like receptors 4; TNF: Tumor necrosis factor; TNFSF10: TNF Superfamily Member 10; TNFa: Tumor necrosis factor alpha; TRAIL: TNF-related apoptosis-inducing ligand; Treg: Regulatory T cells; rTRAIL: Recombinant TRAIL

\section{Acknowledgements}

Not applicable.

\section{Authors' contributions}

ChB drafted and edited the manuscript and prepared figures. AM contributed the part of CNS diseases. GDB contributed the part on TRAIL and Alzheimer's disease. CDF and RDM performed literature searching and drafted the manuscript. FC, CIB, and GC critically reviewed the manuscript. $\mathrm{RB}$ conceived the idea of this review. All authors read and approved the final manuscript.

\section{Funding}

The work has been funded by the PRIN grant n. 2017YH3SXK from the Italian Ministry of Research.

\section{Availability of data and materials}

Not applicable.

\section{Ethics approval and consent to participate}

Not applicable.

\section{Consent for publication}

Not applicable.

\section{Competing interests}

The authors declare that they have no competing interests.

\section{Author details}

${ }^{1}$ Department of Biomedical and Biotechnological Sciences (BIOMETEC), Section of Pharmacology, University of Catania, Via Santa Sofia 97, Catania, Italy. ${ }^{2}$ Department of Drug Sciences, University of Catania, Catania, Italy. ${ }^{3}$ Oasi Research Institute-IRCCS, Troina, Italy. ${ }^{4}$ Clinical Toxicology Unit, University Hospital, University of Catania, Catania, Italy.

Received: 26 May 2020 Accepted: 28 September 2020 Published online: 13 October 2020

\section{References}

1. Querfurth HW, LaFerla FM. Alzheimer's disease. N Engl J Med. 2010;362:32944.

2. Murphy MP, LeVine H. Alzheimer's disease and the amyloid-beta peptide. Alzheimers Dis. 2010;19:311-23.

3. Heneka MT, Golenbock DT, Latz E. Innate immunity in Alzheimer's disease. Nat Immunol. 2015;16:229-36.
4. Chavan SS, Pavlov VA, Tracey KJ. Mechanisms and therapeutic relevance of neuro-immune communication. Immunity. 2017:46:927-42.

5. Kulkarni OP, Lichtnekert J, Anders H-J, Mulay SR. The immune system in tissue environments regaining homeostasis after injury: is "inflammation" always inflammation? Mediators Inflamm. 2016;2016:2856213.

6. Schwartz M, Kipnis J, Rivest S, Prat A. How do immune cells support and shape the brain in health, disease, and aging? J Neurosci. 2013;33:17587-96.

7. Clark SM, Vaughn CN, Soroka JA, Li X, Tonelli LH. Neonatal adoptive transfer of lymphocytes rescues social behaviour during adolescence in immunedeficient mice. Eur J Neurosci. 2018:47:968-78.

8. Lin T, Liu GA, Perez E, Rainer RD, Febo M, Cruz-Almeida Y, et al. Systemic inflammation mediates age-related cognitive deficits. Front Aging Neurosci. 2018;10:236.

9. Chen W-W, Zhang $X$, Huang W-J. Role of neuroinflammation in neurodegenerative diseases (Review). Mol Med Rep. 2016;13:3391-6.

10. Chitnis T, Weiner HL. CNS inflammation and neurodegeneration. J Clin Invest. 2017:127:3577-87.

11. Falschlehner C, Schaefer U, Walczak H. Following TRAll's path in the immune system. Immunology. 2009;127:145-54.

12. Lee H-O, Herndon JM, Barreiro R, Griffith TS, Ferguson TA. TRAlL: a mechanism of tumor surveillance in an immune privileged site. J Immunol. 2002;169:4739-44

13. Cantarella G, Uberti D, Carsana T, Lombardo G, Bernardini R, Memo M. Neutralization of TRAIL death pathway protects human neuronal cell line from beta-amyloid toxicity. Cell Death Differ. 2003;10:134-41.

14. Cantarella G, Di Benedetto G, Scollo M, Paterniti I, Cuzzocrea S, Bosco P, et al. Neutralization of tumor necrosis factor-related apoptosis-inducing ligand reduces spinal cord injury damage in mice. Neuropsychopharmacology. 2010;35:1302-14.

15. Cantarella G, Pignataro G, Di Benedetto G, Anzilotti S, Vinciguerra A, Cuomo $\mathrm{O}$, et al. Ischemic tolerance modulates TRAIL expression and its receptors and generates a neuroprotected phenotype. Cell Death Dis. 2014:5:e1331.

16. Martin-Villalba A, Herr I, Jeremias I, Hahne M, Brandt R, Vogel J, et al. CD95 ligand (Fas-L/APO-1L) and tumor necrosis factor-related apoptosis-inducing ligand mediate ischemia-induced apoptosis in neurons. J Neurosci. 1999;19: 3809-17.

17. Cantarella G, Di Benedetto G, Puzzo D, Privitera L, Loreto C, Saccone S, et al. Neutralization of TNFSF10 ameliorates functional outcome in a murine model of Alzheimer's disease. Brain. 2015;138:203-16.

18. Di Benedetto G, Burgaletto C, Carta AR, Saccone S, Lempereur L, Mulas G, et al. Beneficial effects of curtailing immune susceptibility in an Alzheimer's disease model. J Neuroinflammation. 2019;16:166.

19. Benedetto GD, Saccone S, Lempereur L, Ronsisvalle N, Nocentini G, Bianchini $R$, et al. The proinflammatory cytokine GITRL contributes to TRAlLmediated neurotoxicity in the $\mathrm{HCN}-2$ human neuronal cell line. Curr Alzheimer Res. 2017;14:1090-101.

20. Fu H, Hardy J, Duff KE. Selective vulnerability in neurodegenerative diseases. Nat Neurosci. 2018;21:1350-8.

21. Hammond TR, Marsh SE, Stevens B. Immune signaling in neurodegeneration. Immunity. 2019;50:955-74.

22. Zenaro E, Piacentino G, Constantin G. The blood-brain barrier in Alzheimer's disease. Neurobiol Dis. 2017;107:41-56.

23. Louveau A, Harris TH, Kipnis J. Revisiting the mechanisms of CNS immune privilege. Trends Immunol. 2015;36:569-77.

24. Ghersi-Egea J-F, Strazielle N, Catala M, Silva-Vargas V, Doetsch F, Engelhardt B. Molecular anatomy and functions of the choroidal blood-cerebrospinal fluid barrier in health and disease. Acta Neuropathol. 2018;135:337-61.

25. Fakhoury M. Role of immunity and inflammation in the pathophysiology of neurodegenerative diseases. Neurodegener Dis. 2015;15:63-9.

26. Austin PJ, Moalem-Taylor G. The neuro-immune balance in neuropathic pain: involvement of inflammatory immune cells, immune-like glial cells and cytokines. J Neuroimmunol. 2010;229:26-50.

27. Amor S, Woodroofe MN. Innate and adaptive immune responses in neurodegeneration and repair. Immunology. 2014;141:287-91.

28. Perry VH, Nicoll JAR, Holmes C. Microglia in neurodegenerative disease. Nat Rev Neurol. 2010:6:193-201.

29. Hanisch U-K, Kettenmann H. Microglia: active sensor and versatile effector cells in the normal and pathologic brain. Nat Neurosci. 2007;10:1387-94.

30. Hampel H, Caraci F, Cuello AC, Caruso G, Nisticò R, Corbo M, et al. A path toward precision medicine for neuroinflammatory mechanisms in Alzheimer's disease. Front Immunol. 2020;11:456. 
31. Vukovic J, Colditz MJ, Blackmore DG, Ruitenberg MJ, Bartlett PF. Microglia modulate hippocampal neural precursor activity in response to exercise and aging. J Neurosci. 2012;32:6435-43.

32. Schetters STT, Gomez-Nicola D, Garcia-Vallejo JJ, Van Kooyk Y. Neuroinflammation: microglia and T cells get ready to tango. Front Immunol. 2017:8:1905

33. Jin J-J, Kim H-D, Maxwell JA, Li L, Fukuchi K-I. Toll-like receptor 4-dependent upregulation of cytokines in a transgenic mouse model of Alzheimer's disease. J Neuroinflammation. 2008;5:23.

34. Kreutzberg GW. Microglia: a sensor for pathological events in the CNS Trends Neurosci. 1996;19:312-8.

35. Block ML, Zecca L, Hong J-S. Microglia-mediated neurotoxicity: uncovering the molecular mechanisms. Nat Rev Neurosci. 2007:8:57-69.

36. Tang $Y$, Le W. Differential roles of $M 1$ and $M 2$ microglia in neurodegenerative diseases. Mol Neurobiol. 2016;53:1181-94.

37. Cherry JD, Olschowka JA, O'Banion MK. Neuroinflammation and M2 microglia: the good, the bad, and the inflamed. J Neuroinflammation. 2014; 11:98.

38. González H, Elgueta D, Montoya A, Pacheco R. Neuroimmune regulation of microglial activity involved in neuroinflammation and neurodegenerative diseases. J Neuroimmunol. 2014:274:1-13.

39. Prinz M, Priller J. Microglia and brain macrophages in the molecular age: from origin to neuropsychiatric disease. Nat Rev Neurosci. 2014;15:300-12.

40. Schwartz M, Baruch K. The resolution of neuroinflammation in neurodegeneration: leukocyte recruitment via the choroid plexus. EMBO J. 2014;33:7-22.

41. Schwartz M. Can immunotherapy treat neurodegeneration? Science. 2017; 357:254-5 American Association for the Advancement of Science.

42. Jung S, Schwartz M. Non-identical twins - microglia and monocyte-derived macrophages in acute injury and autoimmune inflammation. Front Immunol. 2012;3:89.

43. Guttenplan KA, Liddelow SA. Astrocytes and microglia: models and tools. J Exp Med. 2019;216:71-83.

44. Lécuyer M-A, Kebir $\mathrm{H}$, Prat A. Glial influences on BBB functions and molecular players in immune cell trafficking. Biochim Biophys Acta. 1862; 2016:472-82.

45. Liddelow SA, Barres BA. Reactive astrocytes: production, function, and therapeutic potential. Immunity. 2017:46:957-67.

46. Dong Y, Benveniste EN. Immune function of astrocytes. Glia. 2001;36:180-90

47. Dong Y, Lagarde J, Xicota L, Corne H, Chantran Y, Chaigneau T, et al. Neutrophil hyperactivation correlates with Alzheimer's disease progression. Ann Neurol. 2018;83:387-405.

48. Jha MK, Jo M, Kim J-H, Suk K. Microglia-astrocyte crosstalk: an intimate molecular conversation. Neuroscientist. 2019;25:227-40.

49. Cekanaviciute E, Buckwalter MS. Astrocytes: integrative regulators of neuroinflammation in stroke and other neurological diseases. Neurotherapeutics. 2016;13:685-701.

50. Nutma E, van Gent D, Amor S, Peferoen LAN. Astrocyte and oligodendrocyte cross-talk in the central nervous system. Cells. 2020;9(3):600.

51. Schwartz M, Deczkowska A. Neurological disease as a failure of brainimmune crosstalk: the multiple faces of neuroinflammation. Trends Immunol. 2016;37:668-79.

52. Cooper MD, Alder MN. The evolution of adaptive immune systems. Cell. 2006;124:815-22

53. Ciccocioppo F, Bologna G, Ercolino E, Pierdomenico L, Simeone P, Lanuti P, et al. Neurodegenerative diseases as proteinopathies-driven immune disorders. Neural Regen Res. 2020;15:850-6.

54. Dendrou CA, Fugger L, Friese MA. Immunopathology of multiple sclerosis. Nat Rev Immunol. 2015;15:545-58.

55. Klotz L, Kuzmanov I, Hucke S, Gross CC, Posevitz V, Dreykluft A, et al. B7-H1 shapes T-cell-mediated brain endothelial cell dysfunction and regional encephalitogenicity in spontaneous CNS autoimmunity. Proc Natl Acad Sci USA. 2016;113:E6182-91.

56. Majerova P, Michalicova A, Cente M, Hanes J, Vegh J, Kittel A, et al. Trafficking of immune cells across the blood-brain barrier is modulated by neurofibrillary pathology in tauopathies. PLoS One. 2019;14:e0217216.

57. Rosenberg GA. Neurological diseases in relation to the blood-brain barrier. $J$ Cereb Blood Flow Metab. 2012;32:1139-51.

58. Alvarez II, Saint-Laurent O, Godschalk A, Terouz S, Briels C, Larouche S, et al. Focal disturbances in the blood-brain barrier are associated with formation of neuroinflammatory lesions. Neurobiol Dis. 2015;74:14-24.
59. Szmydynger-Chodobska J, Strazielle N, Zink BJ, Ghersi-Egea J-F, Chodobsk A. The role of the choroid plexus in neutrophil invasion after traumatic brain injury. J Cereb Blood Flow Metab. 2009;29:1503-16.

60. Paul S, Shilpi, Lal G. Role of gamma-delta $(\gamma \delta)$ T cells in autoimmunity. J Leukoc Biol. 2015;97:259-71.

61. Dardalhon $\mathrm{V}$, Korn T, Kuchroo VK, Anderson AC. Role of Th1 and Th17 cells in organ-specific autoimmunity. J Autoimmun. 2008;31:252-6.

62. Cao C, Arendash GW, Dickson A, Mamcarz MB, Lin X, Ethell DW. Abetaspecific Th2 cells provide cognitive and pathological benefits to Alzheimer's mice without infiltrating the CNS. Neurobiol Dis. 2009;34:63-70.

63. Luckheeram RV, Zhou R, Verma AD, Xia B. CD4 ${ }^{+} T$ cells: differentiation and functions. Clin Dev Immunol. 2012;2012:925135.

64. Schneider-Hohendorf T, Schwab N, Uçeyler N, Göbel K, Sommer C, Wiendl $\mathrm{H}$. CD8+ T-cell immunity in chronic inflammatory demyelinating polyradiculoneuropathy. Neurology. 2012;78:402-8.

65. Fan Z, Zhang Q. Molecular mechanisms of lymphocyte-mediated cytotoxicity. Cell Mol Immunol. 2005;2:259-64.

66. O'Connor RA, Anderton SM. Foxp3+ regulatory T cells in the control of experimental CNS autoimmune disease. J Neuroimmunol. 2008:193:1-11.

67. Allan SE, Broady R, Gregori S, Himmel ME, Locke N, Roncarolo MG, et al. CD4+ T-regulatory cells: toward therapy for human diseases. Immunol Rev. 2008;223:391-421.

68. Martinez-Forero I, Garcia-Munoz R, Martinez-Pasamar S, Inoges S, Lopez-Diaz de Cerio A, Palacios R, et al. IL-10 suppressor activity and ex vivo $\operatorname{Tr} 1$ cell function are impaired in multiple sclerosis. Eur J Immunol. 2008;38:576-86.

69. Reynolds AD, Banerjee R, Liu J, Gendelman HE, Mosley RL. Neuroprotective activities of CD4+CD25+ regulatory T cells in an animal model of Parkinson's disease. J Leukoc Biol. 2007:82:1083-94.

70. Huang Y, Liu Z, Cao B-B, Qiu Y-H, Peng Y-P. Treg Cells Attenuate Neuroinflammation and Protect Neurons in a Mouse Model of Parkinson's Disease. J Neuroimmune Pharmacol. 2020;15:224-37.

71. Dansokho C, Ait Ahmed D, Aid S, Toly-Ndour C, Chaigneau T, Calle V, et al. Regulatory $T$ cells delay disease progression in Alzheimer-like pathology. Brain. 2016:139:1237-51.

72. Tesseur I, Zou K, Esposito L, Bard F, Berber E, Can JV, et al. Deficiency in neuronal TGF-beta signaling promotes neurodegeneration and Alzheimer's pathology. J Clin Invest. 2006;116:3060-9.

73. Caraci F, Spampinato SF, Morgese MG, Tascedda F, Salluzzo MG, Giambirtone MC, et al. Neurobiological links between depression and AD: the role of TGF- $\beta 1$ signaling as a new pharmacological target. Pharmacol Res. 2018;130:374-84.

74. Baruch K, Rosenzweig N, Kertser A, Deczkowska A, Sharif AM, Spinrad A, et al. Breaking immune tolerance by targeting Foxp3(+) regulatory T cells mitigates Alzheimer's disease pathology. Nat Commun. 2015;6:7967.

75. Huang Y, Wang Y, Li X, Chen Z, Li X, Wang H, et al. Molecular mechanism of ER stress-induced gene expression of tumor necrosis factor-related apoptosisinducing ligand (TRAIL) in macrophages. FEBS J. 2015;282:2361-78.

76. Liabakk NB, Sundan A, Torp S, Aukrust P, Frøland SS, Espevik T. Development, characterization and use of monoclonal antibodies against STRAIL: measurement of sTRAIL by ELISA. J Immunol Methods. 2002;259:119-28.

77. Locksley RM, Killeen N, Lenardo MJ. The TNF and TNF receptor superfamilies: integrating mammalian biology. Cell. 2001;104:487-501.

78. Schaefer U, Voloshanenko O, Willen D, Walczak H. TRAlL: a multifunctional cytokine. Front Biosci. 2007;12:3813-24.

79. Di Pietro R, Zauli G. Emerging non-apoptotic functions of tumor necrosis factor-related apoptosis-inducing ligand (TRAIL)/Apo2L. J Cell Physiol. 2004; 201:331-40

80. Yerbes R, Palacios C, López-Rivas A. The therapeutic potential of TRAlL receptor signalling in cancer cells. Clin Transl Oncol. 2011;13:839-47.

81. Zauli G, Melloni E, Capitani S, Secchiero P. Role of full-length osteoprotegerin in tumor cell biology. Cell Mol Life Sci. 2009;66:841-51.

82. Di Benedetto G, Lempereur L, Valle D, Greco EA, Bernardini R, Lenzi A, et al. Redundant modulatory effects of proinflammatory cytokines in human osteoblastic cells in vitro. Clin Exp Rheumatol. 2018:36:959-69.

83. Wu GS, Burns TF, Zhan Y, Alnemri ES, El-Deiry WS. Molecular cloning and functional analysis of the mouse homologue of the KILLER/DR5 tumor necrosis factor-related apoptosis-inducing ligand (TRAIL) death receptor. Cancer Res. 1999:59:2770-5.

84. Rossin A, Miloro G, Hueber A-O. TRAIL and FasL functions in cancer and autoimmune diseases: towards an increasing complexity. Cancers (Basel). 2019;11(5):639. 
85. Sessler T, Healy S, Samali A, Szegezdi E. Structural determinants of DISC function: new insights into death receptor-mediated apoptosis signalling. Pharmacol Ther. 2013;140:186-99.

86. Luo X, Budihardjo I, Zou H, Slaughter C, Wang X. Bid, a Bcl2 interacting protein, mediates cytochrome $\mathrm{c}$ release from mitochondria in response to activation of cell surface death receptors. Cell. 1998:94:481-90.

87. Wiley SR, Schooley K, Smolak PJ, Din WS, Huang CP, Nicholl JK, et al. Identification and characterization of a new member of the TNF family that induces apoptosis. Immunity. 1995;3:673-82.

88. Secchiero P, Milani D, Gonelli A, Melloni E, Campioni D, Gibellini D, et al. Tumor necrosis factor (TNF)-related apoptosis-inducing ligand (TRAIL) and TNF-alpha promote the NF-kappaB-dependent maturation of normal and leukemic myeloid cells. J Leukoc Biol. 2003;74:223-32.

89. Zauli G, Sancilio S, Cataldi A, Sabatini N, Bosco D, Di Pietro R. PI-3K/Akt and NF-kappaB/lkappaBalpha pathways are activated in Jurkat T cells in response to TRAlL treatment. J Cell Physiol. 2005;202:900-11.

90. Toffoli B, Bernardi S, Candido R, Zacchigna S, Fabris B, Secchiero P. TRAlL shows potential cardioprotective activity. Invest New Drugs. 2012;30:1257-60.

91. Cantarella G, Di Benedetto G, Ribatti D, Saccani-Jotti G, Bernardini R. Involvement of caspase 8 and c-FLIPL in the proangiogenic effects of the tumour necrosis factor-related apoptosis-inducing ligand (TRAIL). FEBS J. 2014;281:1505-13.

92. Dörr J, Bechmann I, Waiczies S, Aktas O, Walczak H, Krammer PH, et al. Lack of tumor necrosis factor-related apoptosis-inducing ligand but presence of its receptors in the human brain. J Neurosci. 2002;22:RC209.

93. Kichev A, Rousset Cl, Baburamani AA, Levison SW, Wood TL, Gressens P, et al. Tumor necrosis factor-related apoptosis-inducing ligand (TRAIL) signaling and cell death in the immature central nervous system after hypoxia-ischemia and inflammation. J Biol Chem. 2014;289:9430-9.

94. Ryan LA, Peng H, Erichsen DA, Huang Y, Persidsky Y, Zhou Y, et al. TNFrelated apoptosis-inducing ligand mediates human neuronal apoptosis: links to HIV-1-associated dementia. J Neuroimmunol. 2004;148:127-39.

95. Cantarella G, Risuglia N, Lombardo G, Lempereur L, Nicoletti F, Memo M, et al. Protective effects of estradiol on TRAlL-induced apoptosis in a human oligodendrocytic cell line: evidence for multiple sites of interactions. Cell Death Differ. 2004;11:503-11.

96. Huang $Y$, Erdmann N, Peng H, Zhao $Y$, Zheng J. The role of TNF related apoptosis-inducing ligand in neurodegenerative diseases. Cell Mol Immunol. 2005:2:113-22.

97. Aktas O, Schulze-Topphoff U, Zipp F. The role of TRAIL/TRAIL receptors in central nervous system pathology. Front Biosci. 2007;12:2912-21.

98. Bossi F, Bernardi S, Zauli G, Secchiero P, Fabris B. TRAlL modulates the immune system and protects against the development of diabetes. J Immunol Res. 2015;2015:680749.

99. Cassatella MA, Huber V, Calzetti F, Margotto D, Tamassia N, Peri G, et al. Interferon-activated neutrophils store a TNF-related apoptosis-inducing ligand (TRAIL/Apo-2 ligand) intracellular pool that is readily mobilizable following exposure to proinflammatory mediators. J Leukoc Biol. 2006;79: 123-32

100. Halaas O, Vik R, Ashkenazi A, Espevik T. Lipopolysaccharide induces expression of APO2 ligand/TRAlL in human monocytes and macrophages. Scand J Immunol. 2000;51:244-50.

101. Kahraman A, Barreyro FJ, Bronk SF, Werneburg NW, Mott JL, Akazawa Y, et al. TRAIL mediates liver injury by the innate immune system in the bile duct-ligated mouse. Hepatology. 2008;47:1317-30.

102. Mirandola P, Ponti C, Gobbi G, Sponzilli I, Vaccarezza M, Cocco L, et al. Activated human NK and CD8+ T cells express both TNF-related apoptosisinducing ligand (TRAIL) and TRAIL receptors but are resistant to TRAILmediated cytotoxicity. Blood. 2004;104:2418-24.

103. Lehnert C, Weiswange M, Jeremias I, Bayer C, Grunert M, Debatin K-M, et al. TRAIL-receptor costimulation inhibits proximal TCR signaling and suppresses human T cell activation and proliferation. J Immunol. 2014;193:4021-31.

104. Ren $X$, Ye F, Jiang Z, Chu Y, Xiong S, Wang Y. Involvement of cellular death in TRAIL/DR5-dependent suppression induced by CD4(+)CD25(+) regulatory T cells. Cell Death Differ. 2007;14:2076-84.

105. Phillips TA, Ni J, Pan G, Ruben SM, Wei YF, Pace JL, et al. TRAIL (Apo-2L) and TRAIL receptors in human placentas: implications for immune privilege. J Immunol. 1999;162:6053-9.

106. Lamhamedi-Cherradi S-E, Zheng S-J, Maguschak KA, Peschon J, Chen YH. Defective thymocyte apoptosis and accelerated autoimmune diseases in TRAIL-/- mice. Nat Immunol. 2003;4:255-60.
107. Sag D, Ayyildiz ZO, Gunalp S, Wingender G. The role of TRAIL/DRs in the modulation of immune cells and responses. Cancers (Basel). 2019;11(10): 1469.

108. Chyuan I-T, Tsai H-F, Wu C-S, Sung C-C, Hsu P-N. TRAlL-mediated suppression of $\mathrm{T}$ cell receptor signaling inhibits $\mathrm{T}$ cell activation and inflammation in experimental autoimmune encephalomyelitis. Front Immunol. 2018;9:15

109. Chyuan IT, Tsai HF, Wu CS, Hsu PN. TRAIL suppresses gut inflammation and inhibits colitogeic T-cell activation in experimental colitis via an apoptosisindependent pathway. Mucosal Immunol. 2019;12:980-9.

110. Zoller V, Funcke J-B, Roos J, Dahlhaus M, Abd El Hay M, Holzmann K, et al. Trail (TNF-related apoptosis-inducing ligand) induces an inflammatory response in human adipocytes. Sci Rep. 2017;7:5691.

111. Clarke P, Meintzer SM, Gibson S, Widmann C, Garrington TP, Johnson GL, et al. Reovirus-induced apoptosis is mediated by TRAIL. J Virol. 2000;74: 8135-9.

112. Kuba A, Raida L. Graft versus host disease: from basic pathogenic principles to DNA damage response and cellular senescence. Mediators Inflamm. 2018;2018:9451950.

113. Jameson SC, Hogquist KA, Bevan MJ. Positive selection of thymocytes. Annu Rev Immunol. 1995;13:93-126.

114. Ahmed AA, Nordlind K, Schultzberg M, Lidén S. Proinflammatory cytokines and their corresponding receptor proteins in eccrine sweat glands in normal and cutaneous leishmaniasis human skin. An immunohistochemical study. Exp Dermatol. 1996:5:230-5.

115. Leverkus M, Walczak H, McLellan A, Fries HW, Terbeck G, Bröcker EB, et al. Maturation of dendritic cells leads to up-regulation of cellular FLICEinhibitory protein and concomitant down-regulation of death ligandmediated apoptosis. Blood. 2000;96:2628-31.

116. Corazza N, Brumatti G, Jakob S, Villunger A, Brunner T. TRAlL and thymocyte apoptosis: not so deadly? Cell Death Differ. 2004;11(Suppl 2):S213-5.

117. Ikeda T, Hirata S, Fukushima S, Matsunaga Y, Ito T, Uchino M, et al. Dual effects of TRAIL in suppression of autoimmunity: the inhibition of Th1 cells and the promotion of regulatory T cells. J Immunol. 2010;185:5259-67.

118. Wang SH, Chen G-H, Fan Y, Van Antwerp M, Baker JR. Tumor necrosis factor-related apoptosis-inducing ligand inhibits experimental autoimmune thyroiditis by the expansion of CD4+CD25+ regulatory T cells. Endocrinology. 2009;150:2000-7.

119. Park J-S, Oh Y, Park O, Foss CA, Lim SM, Jo D-G, et al. PEGylated TRAIL ameliorates experimental inflammatory arthritis by regulation of Th17 cells and regulatory T cells. J Control Release. 2017;267:163-71.

120. Song K, Chen Y, Göke R, Wilmen A, Seidel C, Göke A, et al. Tumor necrosis factor-related apoptosis-inducing ligand (TRAIL) is an inhibitor of autoimmune inflammation and cell cycle progression. J Exp Med. 2000;191: 1095-104.

121. Wandinger K-P, Lünemann JD, Wengert $O$, Bellmann-Strobl J, Aktas O, Weber A, et al. TNF-related apoptosis inducing ligand (TRAIL) as a potential response marker for interferon-beta treatment in multiple sclerosis. Lancet. 2003:361:2036-43.

122. Robertson NM, Zangrilli JG, Steplewski A, Hastie A, Lindemeyer RG, Planeta MA, et al. Differential expression of TRAIL and TRAIL receptors in allergic asthmatics following segmental antigen challenge: evidence for a role of TRAlL in eosinophil survival. J Immunol. 2002;169:5986-96.

123. Smyth MJ, Cretney E, Takeda K, Wiltrout RH, Sedger LM, Kayagaki N, et al. Tumor necrosis factor-related apoptosis-inducing ligand (TRAIL) contributes to interferon gamma-dependent natural killer cell protection from tumor metastasis. J Exp Med. 2001;193:661-70.

124. Wattmo C, Londos E, Minthon L. Risk factors that affect life expectancy in Alzheimer's disease: a 15-year follow-up. Dement Geriatr Cogn Disord. 2014; 38:286-99.

125. DeTure MA, Dickson DW. The neuropathological diagnosis of Alzheimer's disease. Mol Neurodegener. 2019;14:32

126. Hoffmann O, Zipp F, Weber JR. Tumour necrosis factor-related apoptosisinducing ligand (TRAIL) in central nervous system inflammation. J Mol Med. 2009;87:753-63.

127. Bronzuoli MR, lacomino A, Steardo L, Scuderi C. Targeting neuroinflammation in Alzheimer's disease. J Inflamm Res. 2016;9:199-208.

128. Chakraborty S, Kaushik DK, Gupta M, Basu A. Inflammasome signaling at the heart of central nervous system pathology. J Neurosci Res. 2010;88:1615-31.

129. Griffin WST. Neuroinflammatory cytokine signaling and Alzheimer's disease. N Engl J Med. 2013;368:770-1. 
130. Uberti D, Cantarella G, Facchetti F, Cafici A, Grasso G, Bernardini R, et al. TRA $L$ is expressed in the brain cells of Alzheimer's disease patients. Neuroreport. 2004;15:579-81.

131. Cantarella G, Lempereur L, D'Alcamo MA, Risuglia N, Cardile V, Pennisi G, et al. Trail interacts redundantly with nitric oxide in rat astrocytes: potentia contribution to neurodegenerative processes. J Neuroimmunol. 2007;182: $41-7$.

132. Di Benedetto G, Valerio O, Lariccia V, Burgaletto C, Lempereur L, Parenti C, et al. Tumor necrosis factor-related apoptosis-inducing ligand reduces the expression of the neuroprotective $\mathrm{Na}+/ \mathrm{Ca} 2+$ exchanger isoform NCX3 in human neuroblastoma SH-SY5Y cells. FEBS J. 2019;286:737-49.

133. Uberti D, Ferrari-Toninelli G, Bonini SA, Sarnico I, Benarese M, Pizzi M, et al. Blockade of the tumor necrosis factor-related apoptosis inducing ligand death receptor DR5 prevents beta-amyloid neurotoxicity. Neuropsychopharmacology. 2007:32:872-80.

134. Anderson KM, Olson KE, Estes KA, Flanagan K, Gendelman HE, Mosley RL. Dual destructive and protective roles of adaptive immunity in neurodegenerative disorders. Transl Neurodegener. 2014;3:25.

135. Louveau A, Plog BA, Antila S, Alitalo K, Nedergaard M, Kipnis J. Understanding the functions and relationships of the glymphatic system and meningeal lymphatics. J Clin Invest. 2017;127:3210-9.

136. Maiuolo J, Gliozzi M, Musolino V, Scicchitano M, Carresi C, Scarano F, et al. The "Frail" brain blood barrier in neurodegenerative diseases: role of early disruption of endothelial cell-to-cell connections. Int J Mol Sci. 2018;19(9): 2693.

137. Nagae T, Araki K, Shimoda Y, Sue LI, Beach TG, Konishi Y. Cytokines and cytokine receptors involved in the pathogenesis of Alzheimer's disease. J Clin Cell Immunol. 2016;7(4):441.

138. Sharma A, Rudra D. Emerging functions of regulatory T cells in tissue homeostasis. Front Immunol. 2018;9:883.

139. Sadlon T, Brown CY, Bandara V, Hope CM, Schjenken JE, Pederson SM, et al. Unravelling the molecular basis for regulatory T-cell plasticity and loss of function in disease. Clin Transl Immunology. 2018;7:e1011.

140. Brunkow ME, Jeffery EW, Hjerrild KA, Paeper B, Clark LB, Yasayko SA, et al. Disruption of a new forkhead/winged-helix protein, scurfin, results in the fatal lymphoproliferative disorder of the scurfy mouse. Nat Genet. 2001;27: 68-73.

\section{Publisher's Note}

Springer Nature remains neutral with regard to jurisdictional claims in published maps and institutional affiliations.

Ready to submit your research? Choose BMC and benefit from:

- fast, convenient online submission

- thorough peer review by experienced researchers in your field

- rapid publication on acceptance

- support for research data, including large and complex data types

- gold Open Access which fosters wider collaboration and increased citations

- maximum visibility for your research: over $100 \mathrm{M}$ website views per year

At $\mathrm{BMC}$, research is always in progress.

Learn more biomedcentral.com/submissions 